\title{
MAINTENANCE SISTEM INFORMASI DENGAN METODE RCM DI PT PRATAMA ABADI INDUSTRI (JX)
}

\author{
Falentino Sembiring ${ }^{1}$ ), Yesi $^{2}$ ), Nunik Destria Arianti ${ }^{3}$ ) \\ 1,2,3)Program Studi Sistem Informasi, Universitas Nusa Putra Sukabumi Jl. Raya Cibolang No. 21 \\ Sukabumi, Jawa Barat, 43152 Indonesia, Tlp. 0266210594 \\ e-mail: falentino.sembiring@nusaputra.ac.id ${ }^{12}$, yesi@gmail.com ${ }^{2)}$, nunik.destria@ nusaputra.ac.id $\stackrel{32}{ }$, \\ * Korespondensi: e-mail: falentino.sembiring @nusaputra.ac.id
}

\begin{abstract}
ABSTRAK
Implementasi penjadwalan preventive maintenance yang menggunakan sistem informasi adalah salah satu cara untuk mempermudah perawatan mesin yang berkala yang dilakukan oleh teknisi. Suatu mesin terdiri dari berbagai komponen utama yang mendukung kelancaran operasi sehingga apabila komponen tersebut mengalami kerusakan maka akan menurunkan kinerja mesin dan berpengaruh kepada efisiensi mesin. Pt Pratama Abadi Industri (JX) merupakan salah satu perusahaan yang bergerak dibidang manufacture shoes di mana sistem perawatan mesin yang belum terencana dan masih menggunakan sistem manual sehingga sering mengalami kerusakan pada mesin, maka untuk menyelesaikan permasalahan tersebut diusulkan dilakukan implementasi penjadwalan preventive maintenance menggunakan sistem informasi. Setelah dilakukan perhitungan dan pembahasan, Hasil perhitungan MTTR adanya penurunan waktu dimana pada tahun 2018 MTTR yaitu 540 menit dan 2019 MTTR 180 menit. Dapat disimpulkan penelitian ini dikatakan MTTR berhasil setelah adanya implementasi sistem penjadwalan preventive maintenance, dengan ini jarak perbaikan mengecil.Dan Hasil perhitungan MTBF bertambahnya waktu dimana pada tahun 2018 MTBF 3240 menit dan 2019 MTBF 3600 menit, dapat disimpulkan penelitian ini dikatakan MTBF berhasil setelah adanya implementasi sistem penjadwalan preventive maintenance, dengan ini jarak kerusakan panjang.
\end{abstract}

Kata Kunci :Teknisi,Reliability Centered Maintenance,Implementasi Sistem Informasi

\begin{abstract}
Scheduling preventive maintenance scheduling that uses an information system is one way to simplify periodic machine maintenance carried out by technicians. A machine consists of various main components that support smooth operation so that if the component is damaged it will reduce engine performance and affect engine efficiency. PT Pratama Abadi Industri (JX) is one of the companies engaged in manufacture shoes where engine maintenance systems are not planned and still use manual systems so that they often experience damage to the engine, so to solve these problems proposed preventive maintenance scheduling is carried out using an information system. After calculation and discussion, the MTTR calculation results have a decrease in the time in 2018 MTTR which is 540 minutes and 2019 MTTR 180 minutes. It can be concluded that this study said MTTR was successful after the implementation of a preventive maintenance scheduling system, with this the repair distance was reduced Kata Kunci :Penjadwalan Preventive, Reliability Centered Maintenance,Implementasi System Information
\end{abstract}




\section{PENDAHULUAN}

Seiring perkembangan zaman, kemajuan systemteknologi dan ilmu pengetahuan membawa manusia kehidupan yang lebih baik. Dimana pola hidup manusia di zaman sekarang lebih cenderung menginginkan system teknologi yang lebih mempermudah dalam aktivitas sehari-hari. Hal ini menuntut perusahaan bagaimana menciptakan system informasi yang mempermudah manusia. sistem adalah satu kesatuan komponen yang saling berhubungan dengan batasan yang jelas bekerja bersama-sama untuk mencapai seperangkat tujuan. Sistem informasi adalah kombinasi dari people, hardware, software, jaringan komunikasi, sumber-sumber data, prosedur dan kebijakan yang terorganisasi dengan baik yang dapat menyimpan, dan menyebarluaskan informasi dalam suatu organisasi.

Orang bergantung pada sistem informasi untuk berkomunikasi antara satu sama lain dengan menggunakan berbagai jenis alat fisik (hardware), perintah dan prosedur pemrosesan informas (software), saluran komunikas (jaringan) dan data yang disimpan (sumber daya data). Seiring dengan berkembangnya teknologi informasi memberikan peran yang sangat penting dalam dunia kerja sehingga sering kali orang menggunakan keunggulan sistem informasi yang ia gunakan sebagai kunci strategi di dunia kerja. Tujuan dari sistem informasi adalah menyediakan informasi yang dipergunakan di dalam perhitungan harga pokok jasa, produk dan tujuan lainya yang di inginkan manajemen.[12]

PT Pratama Abadi Industri (jx) merupakan salah satu perusahaan manufacturing sepatu, yang berlokasi di jalan sukabumi-cianjur Km.14, Blok satong parigi desa titisan kecamatan sukalarang kabupaten sukabumi. Berdasarkan hasil wawancara dan pengamatan yang dilakukan (wawancara personal, 02 Maret 2019) team maintenance telah memiliki schedule preventive maintenance sendiri namun dalam proses pelaksanaan sehari-hari nya, masih melakukan proses penjadwalan sampai penginputan masih menggunakan cara manual, dalam hal ini penjadwalan yang manual melakukan secara tertulis sampai penginputan. Hal tersebut kurang efisien karena aktifitas team maintenance lupa untuk mendata dan menginput schedule prepentive maintenance. Masalah lain yang timbul adalah saat penjadwalan mesin yang belum terlaksana di bulan ini dan yang akan di jadwalkan kembali di bulan depan tidak diketahui atau tidak terdata dan tidak tersistem .

Permasalahan-permasalahan itu, tentunya akan memberikan dampak yang kurang baik terhadap kelancaran saat melakukan maintenance. Sehingga perlu adanya program penjadwalan secara sistem, untuk megatasi masalah-masalah tersebut maka penulis akan membuatkan program penjadwalan yang bertujuan untuk mempermudah team maintenance dalam melaksanakan preventive maintenance. 


\section{LANDASAN TEORI.}

\section{Penelitian Terkait}

Ab-Samet et al. (2012) dalam jurnalnya yang berjudul Effective PreventiveMaintenance Scheduling penelitian ini membuktikan bahwa memisahkan mesin dengan kategori kritis dan non kritis, masing-masing memiliki prioritas yang berbeda. Hal tersebut menjadi langkah penting menuju pemecahan masalah agar terkendali dan memastikan mengurangi nilai downtime selain untuk mengurangi beban kerja teknisi. Hasil dari penelitian ini adalah penerapan schedule preventive maintenance membuktikan tingkat kegagalan mesin dapat berkurang dengan baik san mesin dapat dikelompokan menjadi kritikal serta non kritikal.

\section{Definisi Preventive Maintenance}

Preventive maintenance adalah kegiatan pemeliharaan dan perawatan yang dilakukan untuk mencegah timbulnya kerusakan- kerusakan yang tidak terduga dan menemukan kondisi atau keadaan yang dapat menyebabkan fasilitas produksi mengalami kerusakan pada waktu proses produksi. Jadi, semua fasilitas produksi yang mendapatkan perawatan (preventivemaintenance) akan terjamin kontinuitas kerjanya dan selalu diusahakan dalam kondisi atau keadaan yang siap dipergunakan untuk setiap operasi atau proses produksi pada setiap saat. Adapun manfaatpreventive maintenance :

1. Memperkecil overhaul ( turun mesin ).

2. Mengurangi kemungkinan reparasi berskala besar.

3. Mengurangi biaya kerusakan / pergantian mesin.

4. Memperkecil kemungkinan produk-produk yang rusak.

5. Meminimalkan persediaan suku cadang.

6. Memperkecil hilangnya gaji - gaji tambahan akibat penurunan mesin ( overhaul ).

7. Menurunkan harga satuan dari produk pabrik.

\section{METODOLOGI}

\section{Metode Penelitian}

Menurut Darmadi (2013), Metode penelitian adalah suatu cara ilmiah untuk mendapatkan data dengan tujuan kegunaan tertentu. Cara ilmiah berarti kegiatan penelitian itu berdasarkan pada ciri-ciri ke ilmuan yaitu rasional, empiris dan sistematis. Dari definisi diatas dapat di simpulkan bahwa metode penelitian adalah suatu cara yang bersifat ilmiah dalam mendapatkan data untuk kegunaan tertentu.[2] 
JURSISTEKNI (Jurnal Sistem Informasi dan Teknologi Informasi) Vol 2, No.3, September 2020: Hal 25 - 35

ISSN. P: 2715-1875, E: 2715-1883

\section{Variabel penelitian}

Variabel penelitian yang di teliti terdiri dari,teknisi dan mesin.

\section{Jenis Data}

Berikut ini adalah jenis data yang di ambil dalam penelitian ini:

1. Data kuantitatif adalah data atau informasi yang diperoleh dari data downtime mesin.

2. Data kualitatif adalah data yang di ambil dari wawancara teknisi dan team official engineering.

\section{Metode Reliability Centered Maintenance (RCM)}

Realibility centered maintenance (RCM) adalah sebuah proses yang dilakukan untuk memastikan peralatan operasi melakukan fungsi yang diharapkan sesuai dengan operating context saat ini. Reliability Centered Maintenance merupakan metoda study untuk menghasilkan improvement terhadap peralatan operasi yang ada. Komponen-Komponen RCM, RCM memiliki empat komponen utama yaitu Reaktive maintenance,preventive maintenance,predictive tasting dan inspection dan proactive maintenance.[10]

Mean Time To Repair (MTTR)

Untuk menghitung perkiraan dari nilai MTTR ini adalah sebagai berikut.

$$
\boldsymbol{M T T R}=\frac{\sum \boldsymbol{t}}{\boldsymbol{n}}
$$

MTTR = Mean Time To Repair

$\mathrm{t}=$ Waktu yang diperlukan untuk reparasi.

$\mathrm{n}=$ Jumlah reparasi yang pernah dilakukan.

\subsection{Mean Time Between Failure (MTBF)}

Nilai MTBF dapat dihitung atau diukur dengan membagi antara total waktu masa optimal dengan jumlah kerusakan yang terjadi. Berikut persamaan untuk menghitung nilai MTBF :

MTBF $=\frac{\sum \text { tUptime }}{n}$

MTBF $=$ Mean Time Between Failure

tUptime $=$ Waktu optimal.

$\mathrm{n}=$ Jumlah kerusakan yang terjadi . 


\section{HASIL DAN PEMBAHASAN}

\subsection{Analisis Masalah}

Permasalahan yang terdapat didepartement engineering PT Pratama Abadi Industri JX adalah mengenai proses yang masih menggunakan foam atau dokumen, mulai dari penginputan data mesin, pembuatan schedulemaintenance mesin, mengisi data schedule mesin dan report hasil maintenance dari setiap teknisi.

\subsection{Daftar Pertanyaan Wawancara}

Daftar pertanyaan wawancara ini berfungsi untuk menjawab rumusan masalah pada penelitian yang berjudul "Implementasi Penjadwalan Preventive Maintenance SistemInformasi Dengan Metode Rcm di PT Pratama Abadi Industri (jx). Berikut daftar pertanyaan wawancara untuk menjawab rumusan masalah bagaimana Implementasi Penjadwalan Preventive Maintenance SistemInformasi Dengan Metode Rcm di PT Pratama Abadi Industri (jx).

Daftar pertanyaan :

1. Apakah team teknisi mempunyai penjadwalan preventive maintenance?

2. Bagaimana proses penjadwalan preventive maintenance?

3. Apakah sering terjadinya downtime mesin?

4. Berapa jumlah karyawan teknisi?

5. Berapa jumlah total mesin?

6. Bagaimana cara untuk mengetahui nilai dari MTTR saat melakukan schedule preventive maintenance.

7. Bagaimana cara untuk mengetahui nilai dari MTBF saat melakukan schedule preventive maintenance.

8. Bagaimana untuk mengetahui item check di dalam penjadwalan preventive maintenance.

9. Bagaimana untuk mengetahui nama pic atau yang bertanggung jawab saat akan melaksanakan preventive maintenance.

10. Bagaimana cara mengetahui penjadwalan preventive maintenance yang sudah dikerjakan.

Jawaban:

1.Preventive maintenance sudah mempunyai penjadwalan, tetapi masih menggunakan foam (manual).

2. Proses preventive maintenance pertama admin menjadwalkan team teknisi dan menginput mesin setelah itu di print out dan dibagikan ke masing-masing teknisi.

3.Sering terjadinya downtime dikarnakan dalam pelaksanaan penjadwalan preventive maintenance kurang efektive dikarnakan foam yang sering tercecer atau hilang. 
4. Jumlah teknisi kurang lebih 40.

5. Jumlah mesin 80 .

6. Untuk melihat MTTR hanya bisa di lihat di sistem downtime.

7. Untuk melihat MTBF hanya bisa di lihat di sistem downtime.

8. Tidak adanya item check.

9. Tidak dicantumkannya PIC teknisi tersebut.

10. Team teknisi menceklis atau memberi tanda penjadwalan yang sudah dikerjakan di dalam foam.

\section{Perancangan Sistem/ Design}

\section{Use Case Diagram}

Use case diagram ini menjelaskan tentang alus sistem yang akan dibangun untuk menentukan jadwal perbaikan mesin, Use case diagram ini mencakup semua sistem mulai dari aktor dan interaksi Use case nya, berikut adalah gambar use case dari pembuatan jadwal perbaikan mesin.

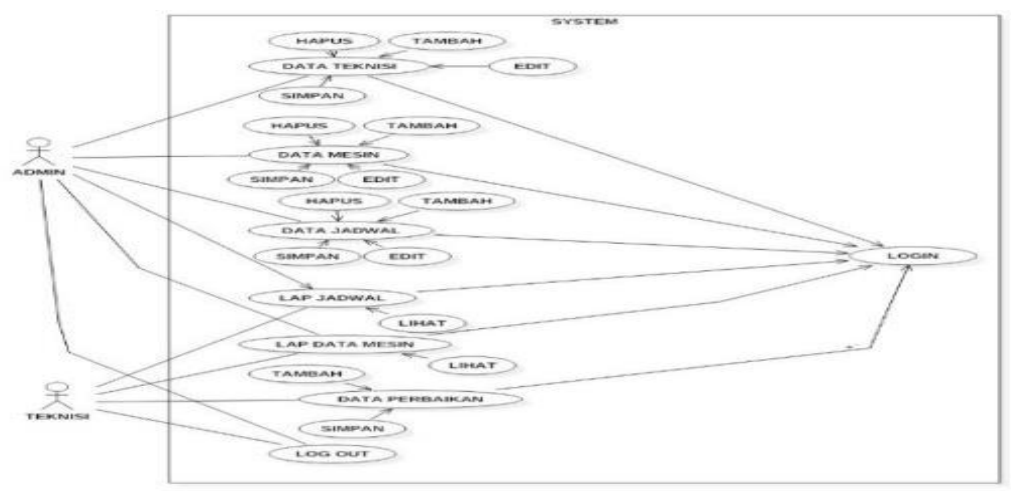

Gambar 4.1 use case diagram menu pengolahan data

\section{Activity Diagram}

a. Activity diagram Login

Activity Diagram Login menjelaskan tentang proses login user (admin dan teknisi) sebelum mengakses sistem pembuatan jadwal perbaikan mesin, berikut ini adalah Activity Diagram Login 
JURSISTEKNI (Jurnal Sistem Informasi dan Teknologi Informasi) Vol 2, No.3, September 2020: Hal $25-35$

ISSN. P: 2715-1875, E: 2715-1883

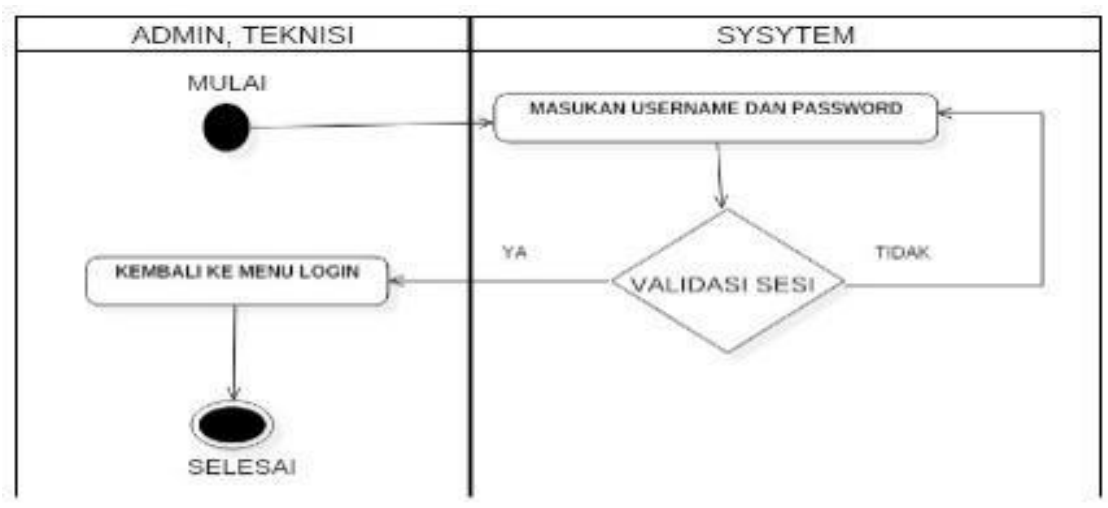

Gambar 4.2Activity Diagram Login

b. Activity diagram pendaftaran user

Activity Diagram pendaftaran menjelaskan tentang proses penambahan user oleh $\operatorname{admin}$

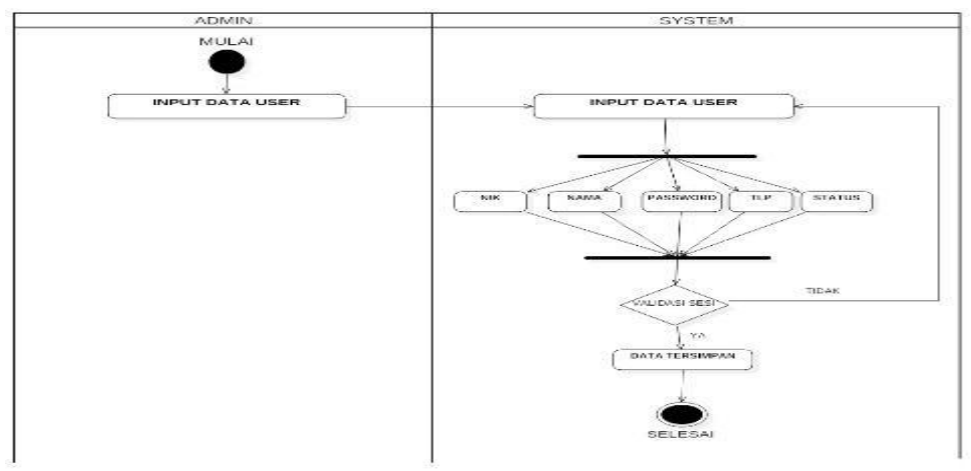

Gambar 4.3 Activity diagram pendaftaran user

c. Activity diagram input data mesin

Activity Diagram input data mesin menjelaskan tentang proses penambahan mesin oleh admin 


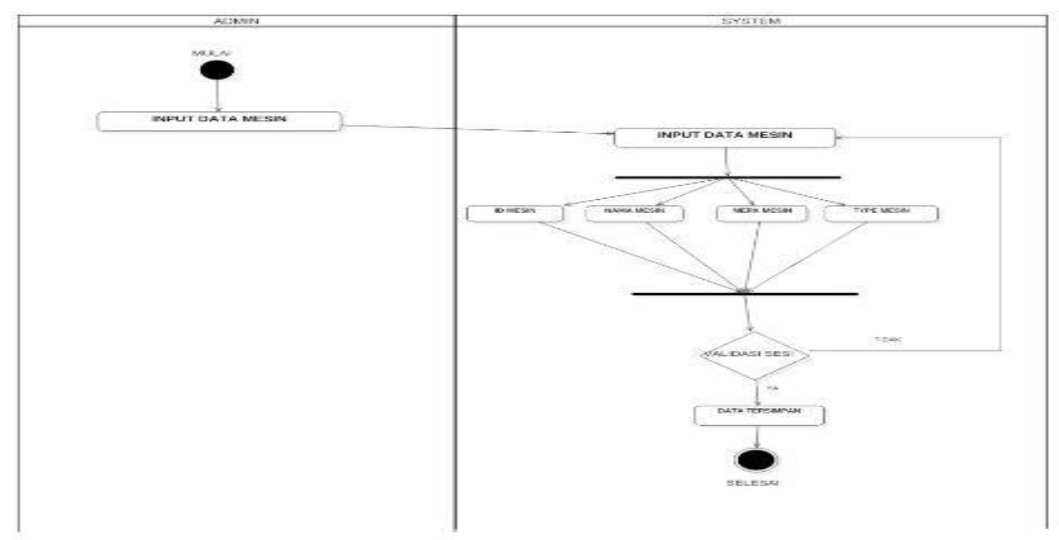

Gambar 4.4 Activity diagram input data mesin

d. Activity diagram input jadwal perbaikan

Activity Diagram input jadwal perbaikan menjelaskan tentang proses pembuatan jadwal perbaikan oleh admin

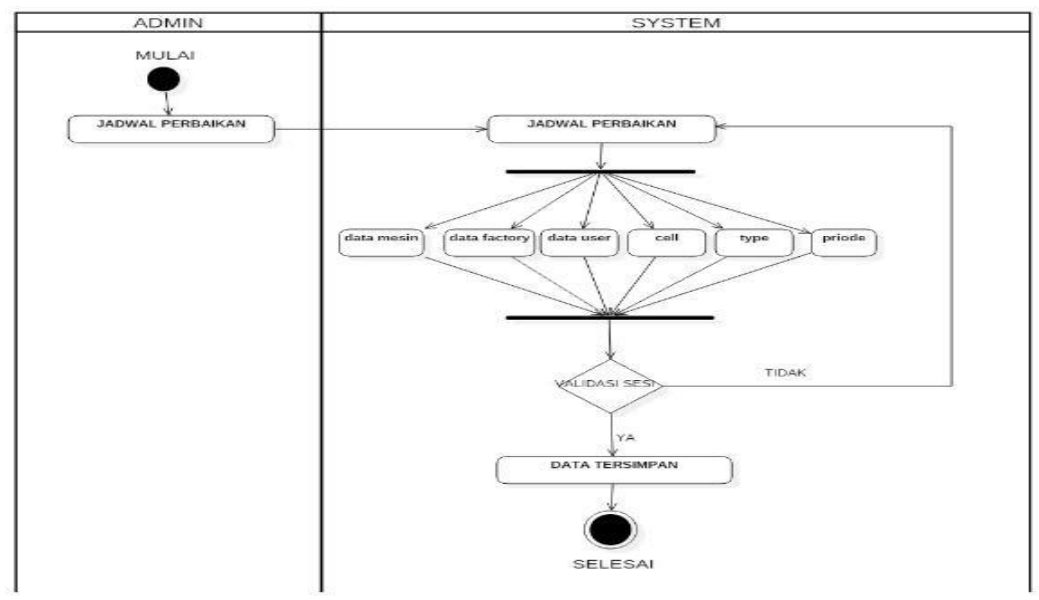

Gambar 4.5 Activity diagram input jadwal Perbaikan

e. Activity diagram isi data perbaikan

Activity Diagram isi data perbaikan menjelaskan tentang proses mengisi data perbaikan oleh teknisi. 
JURSISTEKNI (Jurnal Sistem Informasi dan Teknologi Informasi) Vol 2, No.3, September 2020: Hal $25-35$

ISSN. P: 2715-1875, E: 2715-1883

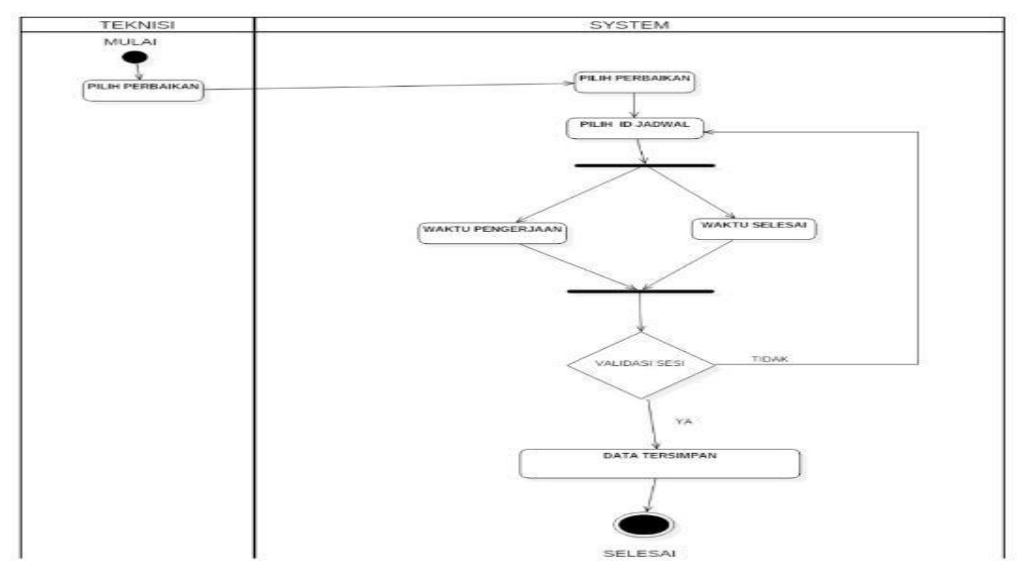

Gambar 4.6 Activity diagram input perbaikan

\section{Class Diagram}

Class Diagram menggambarkan beberapa class yang berada dalam sistem penjadwalan perbaikan mesin yang saling berhubungan. Berikut ini adalah Class Diagram Sistem penjadwalan perbaikan mesin.

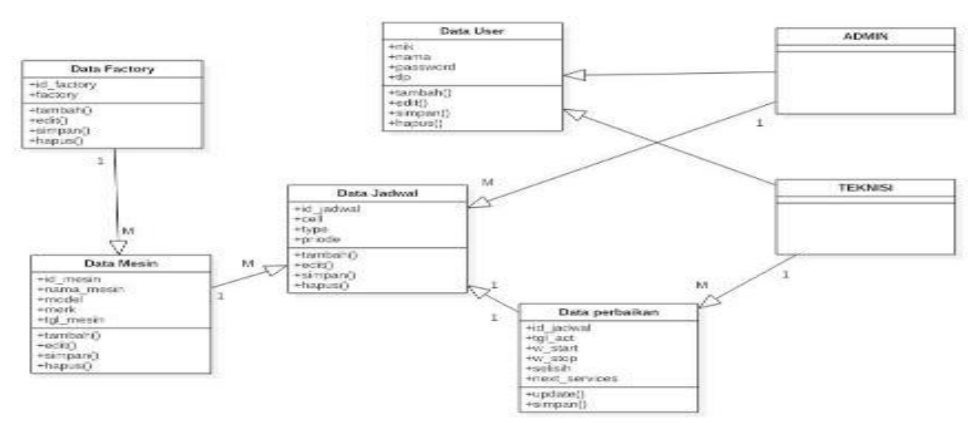

Gambar 4.7. Class Diagram

\section{Implementasi dan Testing}

a. Login

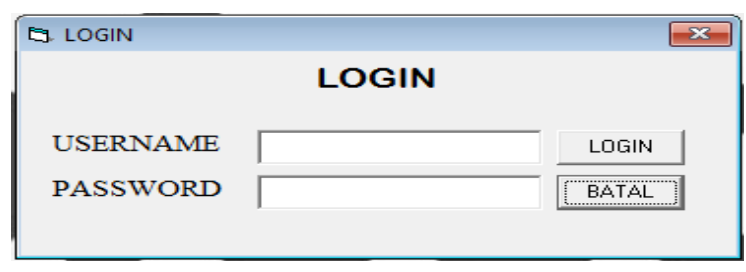

Gambar 4.8Form Login 
b. From jadwal

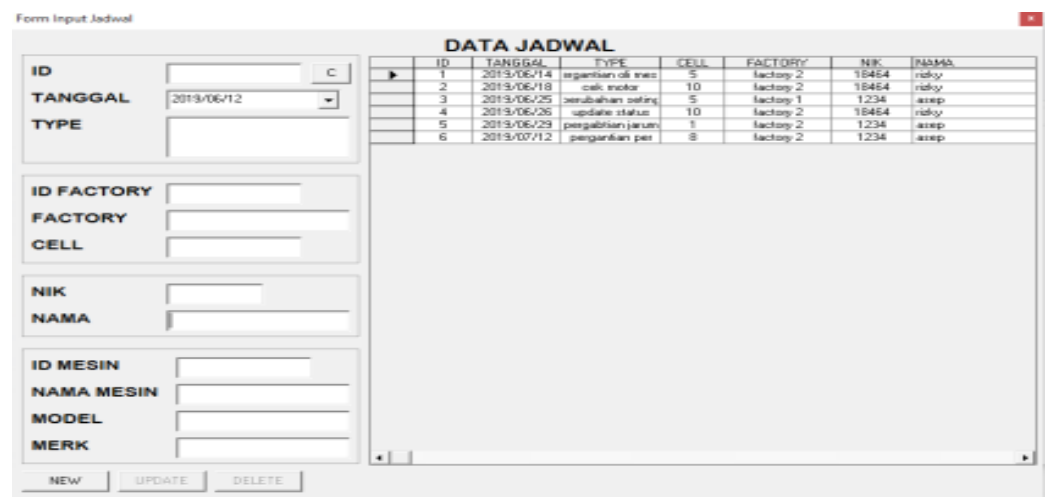

Gambar 4. 9 Form data jadwal

\section{Hasil Analisa Perhitungan MTTR dan MTBF}

Berdasarkan perhitungan MTTR dimana total waktu perbaikan di bagi dengan jumlah perbaikan dan akan terlihat hasilnya dalam menit atau jam. Perhitungan MTBF dimana total jam kerja yaitu tujuh jam kerja di kali jumlah kerusakan yang terjadi di kurang total waktu perbaikan di bagi jumlah kerusakan. Berdasarkan hasil perhitungan MTTR dan MTBF pada tahun 2018 dan 2019 yaitu adanya perbedaan jam, parameter dikatakan berhasil pada penelitian ini MTTR harus lebih kecil di tahun 2019 dari tahun 2018 dalam hal ini waktu(jam,menit,detik). Sedangkan MTBF harus lebis besar di tahun 2019 dari tahun 2019 dalam hal ini waktu(jam,menit,detik).

\section{KESIMPULAN}

Berdasarkan hasil dan pembahasan yang telah dijelaskan pada bab-bab sebelumnya maka dapat dibuatkan kesimpulan sebagai berikut :

1. Implementasi sistem penjadwalan preventive maintenance menggunakan sistem dapat membantu mempermudah team maintenance untuk membagi jadwal perbaikan menggunakan sistem.dimana sebelum adanya sistem perawatan banyak kerusakan yang mendadak dalam hal ini downtime yang mengakibatkan kerugian/cost bagi perusahaan.

2. Hasil perhitungan MTTR adanya penurunan waktu dimana pada tahun 2018 MTTR yaitu 540 menit dan 2019 MTTR 180 menit. Dapat di simpulkan penelitian ini dikatakan MTTR berhasil setelah adanya implementasi sistem penjadwalan preventive maintenance, dengan ini jarak perbaikan menurun.

3. Hasil perhitungan MTBF bertambahnya waktu dimana pada tahun 2018 MTBF 3240 menit dan 2019 MTBF 3600 menit.. dapat disimpulkan penelitian ini dikatakan MTBF berhasil setelah adanya implementasi sistem penjadwalan preventive maintenance, dengan ini jarak kerusakan panjang. 
JURSISTEKNI (Jurnal Sistem Informasi dan Teknologi Informasi) Vol 2, No.3, September 2020: Hal $25-35$

ISSN. P: 2715-1875, E: 2715-1883

\section{DAFTAR PUSTAKA}

[1] Baker, K.R. \& Trietsch, D., 2009. Principles Of Sequencing And Scheduling, New Jersey: John Wiley \& Sons.

[2] Bentley, et al.,System Analys \& Design For The Global Enterprise, New York : Mc Grawhill International Edition, 2007

[3] Darmadi, Hamid. 2013. Metode Penelitian Pendidikan dan Sosial. Bandung: Alfabeta

[4] Putu (2011). "Sistem Informasi dan Implementasinya" Bandung: Informatika.

[5] Menurut Andi(2002) microsoft Visual Basic 6.0 https:// bahasape mogra m anw ord.wordpress.com/definisi-visual-basic-6-0/

[6] Menurut Hanifah Harsono (2002:67), https:/ /www.gur upendidikan. co. id/9-pengertianimplementasi-menurut-para-ahli/

[7] Menurut Solichin Abdul Wahab (1997:63), https://ww w.gurupendidi kan.c o.id/9pengertian-implementasi-menurut-para-ahli/

[8] Menurut Prof. Tachjan (2006) https:// www.sep utarpenget ahuan.co.id /2017/ 06/16pengertian-implementasi-menurut-para-ahli.html

[9] Menurut Nurdin Usman (2002:70) https://www.gurupendidikan.co.id/9-pe ngertianimplementasi-menurut-para-ahli/

[10] ANALISA_METODE_CLASSIC_LIFE_CYCLE_WATERFAL L_U NTUK PEN GEMBANGAN_PERANGKAT 